\title{
Nodular Dermatofibrosis Associated to a Bilateral Renal Cystadenoma in a Dog: Case Report
}

\author{
${ }^{1}$ Universidade Estadual Paulista "Júlio de Mesquita Filho"-UNESP-Jaboticabal, SP, Brazil \\ ${ }^{2}$ Universidade Estadual do Centro Oeste-UNICENTRO-Guarapuava, PR, Brazil \\ ${ }^{3}$ Universidade Regional de Blumenau-FURB-Blumenau, SC, Brazil \\ ${ }^{4}$ Faculdades Integradas de Ourinhos, Bandeirantes, PR, Brazil
}

Ferreira MGPA ${ }^{1,2, *}$, Pascoli $A L^{1,3}$, Olinger $C^{3}$, Antunes $\mathrm{AV}^{2}$, Reis Filho $\mathrm{NP}^{1,4}$, Rolemberg $\mathrm{DS}^{1}$, Costa $\mathrm{MT}^{1}$, and $\mathrm{Nardi}^{\mathrm{A}} \mathrm{B}^{1}$

"Corresponding author: Ferreira MGPA, Universidade Estadual Paulista "Júlio de Mesquita Filho"-UNESP-Jaboticabal, SP, Brazil, Phone: 55-1195348-3104; E-mail: mary_pops1@hotmail.com

Received: 09 Mar, 2020 | Accepted: 24 Mar, 2020 | Published: 31 Mar, 2020

Citation: Ferreira MGPA, Pascoli AL, Olinger C, Antunes AV, Reis Filho NP, et al. (2020) Nodular Dermatofibrosis Associated to a Bilateral Renal Cystadenoma in a Dog: Case Report. Int J Cancer Res Mol Mech 5(1): dx.doi.org/10.16966/2381-3318.145

Copyright: ( 2020 Ferreira MGPA, et al. This is an open-access article distributed under the terms of the Creative Commons Attribution License, which permits unrestricted use, distribution, and reproduction in any medium, provided the original author and source are credited.

\begin{abstract}
The purpose of this study was to describe a nodular dermatofibrosis associated to a bilateral renal cystadenoma in a seven-year old mixed breed female dog. The patient had multiple nodules in its head, ears, limbs, chest, mamae and flank. At physical examination, it was possible to identify a volume expansion of the para-lumbar mesogastric region as well as abdominal painful sensitivity at palpation. The patient underwent abdominal ultrasound, in which it was identified cysts on the left and right renal cortical measuring $7,3 \mathrm{~cm} \times 5,1 \mathrm{~cm}$ and $1,0 \times 1,0 \mathrm{~cm}$ in diameter, respectively. Aspiration and cytology of the skin nodules were performed but the analysis was inconclusive. After biopsy of cutaneous nodules and renal lesions, histopathological analysis was respectively compatible with nodular dermatofibrosis and cystic renal adenoma. Due to the size of the left kidney cyst, partial nephrectomy was suggested; however the owner chose to continue only with clinical following-up. The patient survived for nine months, passing away due to the rupture of the kidney cyst. Reporting an unusual case contributes to differential diagnosis of other conditions, since both diagnosis and therapeutics of this disease are not completely defined in the scientific literature.
\end{abstract}

Keywords: Canine; Neoplasm; Paraneoplastic Syndrome

\section{Introduction}

Primary urinary system neoplasms are rare, comprising approximately $1 \%$ of the tumors in dogs [1], and its etiology in cats and dogs is still unknown [2]. Adenomas are rare benign neoplasms, which derive from epithelial tissue and are usually accidental findings, characterized by a single cortical, rounded and circumscribed mass of up to two centimeters in diameter. Renal cystadenoma is a rare benign neoplasm derived from epithelial tissue defined by accumulations of retained secretions in kidneys [2].

Clinical signs of patients with renal neoplasms are usually nonspecific and depend on the extension of the lesions. Most common clinical signs are apathy, anorexia, vomiting, progressive weight loss and diarrhea [3]. At clinical examination abdominal masses, renomegaly and abdominal tenderness may be identified [2].

Main differential diagnoses for renal cystadenoma include perirenal cysts, renal pseudocysts, polycystic kidneys, abscesses, hematomas, granulomas and echinococcosis [4].

Imaging is crucial for localization, dimensioning and characterization of renal morphological components. Radiography can show a significant increase of renal parenchyma size and excretory urography can delimit the extension of the lesions and evaluate renal function [2].

Kidney ultrasound may reveal the presence of anechoic or hypoechoic structures that characterize cystic accumulations; and thorax X-ray and abdominal ultrasonography are important in order to detect possible distant metastases [5].

Recommended surgical treatment for malignant renal neoplasms when metastasis is not present is complete unilateral nephrectomy of the affected kidney, decreasing pressure on other abdominal organs. Before surgical procedure, evaluation of the opposite kidney's function is required, since bilateral renal dysfunction may lead to a worse prognosis. Partial nephrectomy can be indicated in cases of benign focal lesions or if it is necessary to preserve renal function because of bilateral dysfunction [6].

Some neoplasms may promote changes in sites distant from their primary tumor; sometimes these changes are not directly related to the tumor and/or their metastases and are called paraneoplastic syndromes (PNS) [7]. Clinical signs are generally caused by 
production and releasing of humoral substances in bloodstream, causing effects at distant sites from the primary tumor [8].

Nodular dermatofibrosis is a rare paraneoplastic syndrome manifested by the appearance of multiple cutaneous lesions, usually associated to cystadenocarcinoma or renal cystadenoma and uterine leiomyoma in female animals [7-9]. Thus, this syndrome is a skin marker for the presence of cystadenocarcinoma or renal cystadenoma [1].

Multiple nodules are firm, loose, painless, circumscribed, slow growing, ranging from 0,2 to 5 centimeters in diameter $[3,5]$. Nodular lesions are usually diffuse; however they are most commonly seen in limbs, head, neck, chest and abdominal region [9]. Limb lesions are mainly situated between the digits or on the pads can ulcerate and cause lameness $[3,1]$.

Diagnosis is confirmed by the presence of cutaneous lesions associated with general nonspecific symptoms, skin biopsy and renal ultrasonography. Histopathologic analysis of nodules may reveal proliferation of collagen fibers $[3,5]$.

There is no therapeutics for nodular dermatofibrosis, however ulcerated nodules can be surgically removed [5].

The course of the illness can be long and the prognosis bad, since it is a systemic disorder. Because it is a hereditary condition, it is recommended to inform the owners that the affected animals should not reproduce [3].

Nodular dermatofibrosis is a PNS that establishes a cutaneous marker for cystadenocarcinoma or renal cystadenoma and may precede clinical changes compatible with a terminal renal injury [1].

According to Guaguère E, et al. [5], relation between cutaneous nodules and renal cystadenoma/cystadenocarcinoma is not so clear. Although in most cases cutaneous nodules are detected before renal injury, is it difficult to estimate whether they occur at the same time or if one precedes the other. It is possible that cutaneous nodules and renal cystadenomas or cystadenocarcinomas occur independently but have a common hereditary factor.

\section{Case Report}

A seven-year old mongrel female dog was admitted at UNESP's Veterinary Hospital Governador Laudo Natel located in Jaboticabal, São Paulo - Brazil, showing multiple firm, circumscribed, painless nodules in its head (Figure 1A), ears, limbs (Figure 1B), chest, mamae and flank that had appeared eight months earlier. Physical examination revealed a volume expansion of the para-lumbar mesogastric region and discrete abdominal painful sensitivity.

No changes in hemogram, serum biochemistry and urinalysis were found. The patient was then submitted to abdominal ultrasound, that showed the presence of a cystic structure in the left kidney cortex measuring $7,3 \mathrm{~cm} \times 5,1 \mathrm{~cm}$ (Figure 2), and in the right kidney cortex size $1,0 \mathrm{~cm} \times 1,0 \mathrm{~cm}$. Thorax X-rays showed no images compatible with metastases.

Fine needle aspiration (FNA) of the cutaneous nodules was performed; however results of cytology were inconclusive. Subsequently, punch biopsy of some of the cutaneous nodules and incisional biopsy from renal lesions via ventral midline laparotomy were performed. Left renal histopathological analyze shown a lined single layer of cuboidal epithelium, multifocal papillary proliferations of the tubular epithelium into the lumina of the cysts. Small nests and tubules of epithelial cells were evident within the fibrous cores of the projections. The epithelial cells had minimal pleomorphism and low mitotic activity, compatible with renal adenoma. The skin microscopic examination shown irregular bundles of dense collagen fibers with few fibrocytes. There was no marked demarcation from the surrounding connective tissue, compatible with compatible with nodular dermatofibrosis

Due to the size of the left kidney cyst, partial nephrectomy was suggested, although the owner chose to continue only with clinical following-up. The patient passed away nine months after diagnosis, due to rupture of the kidney cyst.

\section{Discussion}

Although nodular dermatofibrosis associated to renal cystadenoma is a rare paraneoplastic syndrome [7-9], its occurrence has already been reported by Suter M, et al. [10], Moe L, et al. [6], White SD, et al. [11], Langohr IM, et al. [3], Alves CE, et al. [12].

The patient in this study was seven years old, data that corroborates with what Carvalho MB, et al. [2] and Alves CE, et al. [12] cite: kidney tumors are more common in dogs between six and nine years old.

Renal cystadenocarcinoma and nodular dermatofibrosis is a rare inherited cancer syndrome, observed predominantly in the German shepherd dog breed and more rarely in other breeds including the Golden retriever, boxer, Australian shepherd dog and mixed-breed dogs [13]. No information was found in literature regarding racial and sexual predisposition $[11,12]$.

Forty-three of the 45 German shepherd dogs with primary renal tumors had a bilateral and multifocal renal cystadenocarcinomas and a numerous cutaneous nodules. Metastases were found in ten of the 23 dogs. Pedigree analysis strongly indicates that the syndrome is hereditary, probably in an autosomal dominant pattern [14].

In this case report, the patient showed multiple nodules in its head, ears, limbs, chest, mamae and flank, corroborating with Turek MM [9], who cites that nodal lesions are usually diffuse, but are more commonly observed in limbs, head, neck, chest and abdominal region. As observed in this case, Langohr IM, et al. and Guaguère E, et al. $[3,5]$ also described the slow growth of the nodules, which are firm, circumscribed and painless lesions.

Ciccarelli S, et al. [15] described an atypical case of renal cystadenocarcinoma and nodular dermatofibrosis in a neutered 5 -year-old female mixed-breed dog with a clinical presentation of the cutaneous nodules in head, neck and limbs, but an unusual feature of this case involved just one kidney. If renal cystadenocarcinoma is unilateral and there is no evidence of metastasis, nephrectomy may be curative. After nephrectomy, the cutaneous nodules increased in size and number. These same authors reported that nodular dermatofibrosis may not be a paraneoplastic syndrome, but a genetic disease linked to the mutation in the FLCN gene. Also, in human medicine, the aetiopathogenesis of cutaneous fibrofolliculomas and nodular dermatofibrosis is believed to be associated with haplo-insufficiency of the FLCN gene, instead being a paraneoplastic syndrome.

Clinical signs of patients with kidney neoplasms are usually nonspecific [3], and the presence of abdominal masses, renomegaly and painful sensitivity at palpation may be identified [2]; aspects similar to that observed in this case report, in which there was a volume expansion in para-lumbar mesogastric region and abdominal painful sensitivity. 


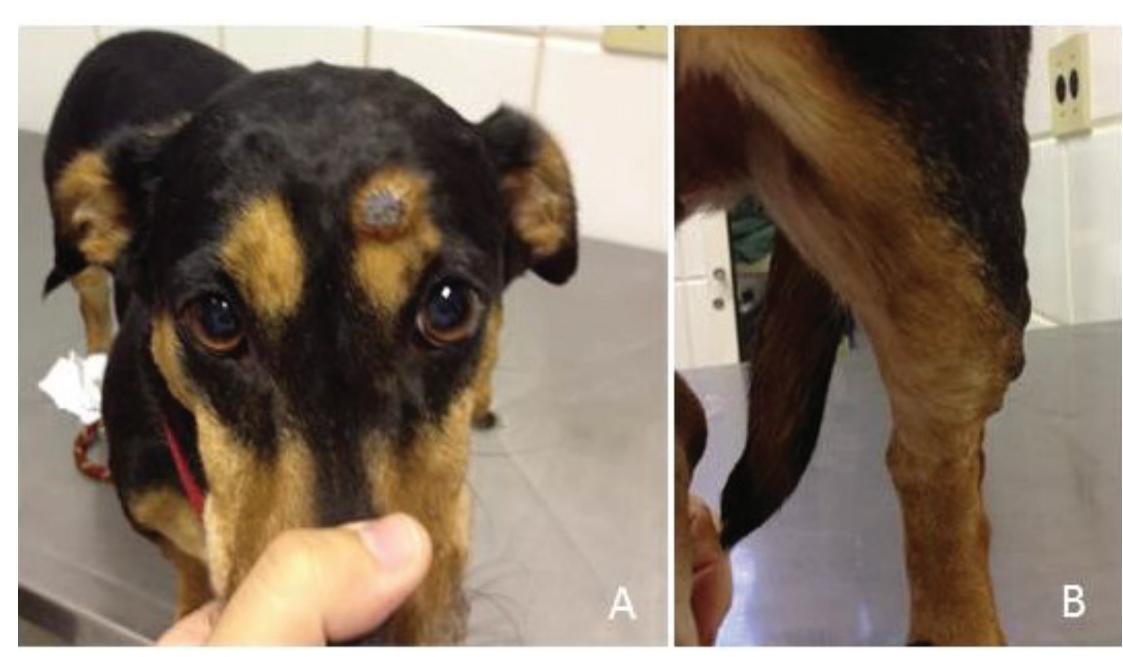

Figure 1: Seven-year old mixed breed female dog with nodular dermatofibrosis.

A. Presence of skin nodules in the head. B. Multiple skin nodules in the left hindlimb.

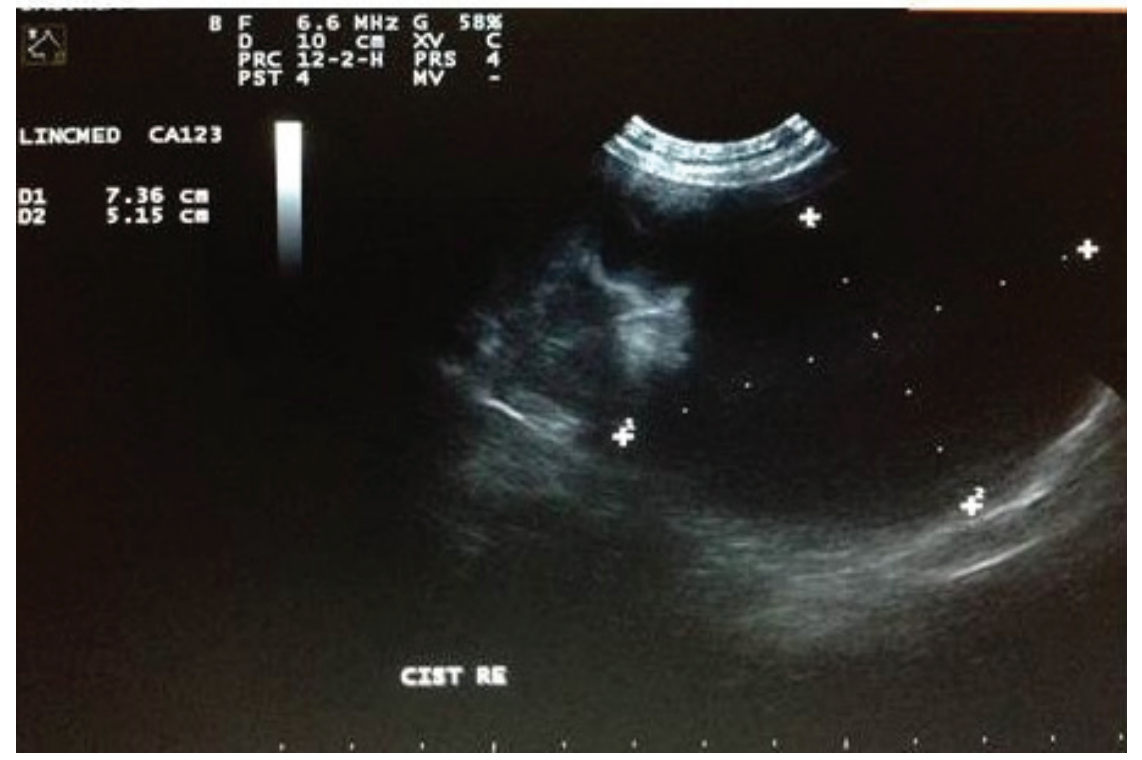

Figure 2: Ultrasound imaging showing a cyst in left kidney cortex of a seven-year old mixed breed female dog.

Mosenco AS, et al. [16], who also did not describe abnormalities in complete blood count, serum biochemistry and total thyroxine, confirm no alterations in hemogram and biochemical profile. However these authors report alterations in urinalysis (proteinuria, hematuria and urinary density), which were not observed in this report. Abdominal ultrasound showed a cystic structure in both kidneys cortical, agreeing with Guaguère E, et al. [5], who affirm that cystic accumulations in kidneys can be easily identified in abdominal ultrasonography and with Mosenco AS, et al. [16], who described ultrasonographic findings of renal cysts in the left kidney of an eleven-year old domestic feline.

The patient in this case had renal cysts in both kidneys, and although nephrectomy was suggested, tutor chose not to submit the patient to surgery. According to Moe L, et al. [6], unilateral nephrectomy is indicated to relieve pressure exerted on other abdominal organs.
According to Langohr IM, et al. [3], early detection of renal tumor is possible by computed tomography at four to five years old, making it possible to avoid reproduction of affected animals, given the hereditary character of this syndrome. Renal biopsy is another way to detect if animals under one year old are carriers of this syndrome, before introducing them to reproduction.

Definitive diagnosis of this condition is established by histopathological analysis of both kidneys lesions, together with skin lesions. Cutaneous biopsy should be performed first, to observe dense collagen proliferation in histopathological analysis [3,9,5]. According to Mosenco AS, et al. [16], it is possible to perform ultrasound-guided drainage of cystic content for cytological and aerobic analysis.

Because cystadenoma is a benign neoplasm, prognosis is good, but it is necessary to evaluate size and site of the lesions in order to 
avoid complications due to compression or obstruction. The cystic structure of the patient in this study was bulky and according to Eustace R, et al. [4], it could displace and compress adjacent organs, such as the intestine. The dog came to death due to cyst rupturing, corroborating with Langohr IM, et al. [3] who reported a sudden death of a dog with the same illness as this study's patient, and subsequently, at necroscopic examination, the presence of hemoperitoneum associated with a renal cyst rupture was confirmed.

\section{Conclusion}

In this case report it was possible to observe nonspecific clinical signs of the patient, therefore the results of complementary tests for the correct diagnosis and the appropriate therapeutic management became very important.

Case reports are important in order to obtain data and prevalence of affections that are not often described in literature. Thus, it is believed that case reports can increase the range of differential diagnoses for patients with the same clinical aspects, laboratory and imaging results, making diagnosis and therapeutic management easier in veterinary medicine.

\section{References}

1. CM Kahn, Line S (2008) Sistema tegumentar. Manual Merck de Veterinária. $9^{\text {th }}$ Edition. São Paulo: Roca 563-680.

2. Carvalho MB, Brum AM, Vasconcellos AL, Alves MAMK (2016) Neoplasias do Sistema Urinário. In: Daleck CR, De Nardi AB (eds) Oncologia Em Cães E Gatos. $2^{\text {nd }}$ Edition. Rio de Janeiro: Roca 37: 675697.

3. Langohr IM, Irigoyen LF, Salles MWS, Kommers GD, de Barros CSL (2002) Cistadenocarcinoma renal e dermatofibrose nodular em cães pastor alemão: 4 casos. Ciência Rural 32: 621-626.

4. Eustace R, Rubin J, Thompson KA, Snowdon K, Sikarskie JG, et al. (2017) Diagnosis and treatment of a unilateral renal cystadenoma in a African lion (Panthera leo). J Zoo Wildl Med 48: 906-909.
5. Guaguèrea E, Hubert T, Muller A (2005) Manifestations cutanées des maladies internes du chien: Cutaneous lesions associated with internal diseases in dogs. EMC-Vétérinaire 119-139.

6. Moe L, Lium B (1997) Hereditary multifocal renal cystadenocarcinomas and nodular dermatofibrosis in 51 German shepherd dogs. J Small Anim Pract 38: 498-505.

7. de Oliveira KM, Dos Santos Horta R, Osório Silva DH, Lavor MSL (2013) Principais síndromes paraneoplásicas em cães e gatos. Enciclopédia Biosfera 9: 2073-2088.

8. Ferreira MGPA, Pascoli AL, Rodigheri SM, Filho NPR, Pazzini JM, et al. (2018) Síndromes paraneoplásicas em cães e gatos: Revisão De Literatura-Parte 2. Investigação 17: 35-42.

9. Turek MM (2003) Cutaneous paraneoplastic syndromes in dogs and cats: a review of the literature. Vet Dermatol 14: 279-296.

10. Suter M, Lott-Stolz G, Wild P (1983) Generalized Nodular Dermatofibrosis in six Alsatians. Vet Pathol 20: 632-634.

11. White SD, Rosychuk RAW, Schultheiss P, Scott KV (1998) Nodular dermatofibrosis and cystic renal disease in three mixed-breed dogs and a Boxer dog. Vet Dermatol 9: 119-126.

12. Alves CE, Corrêa AG, Costa Sdos S, Calazans SG (2013) Nodular dermatofibrosis in a German shepherd dog: case report. Pak J Biol Sci 16: 1623-1625.

13. Zanatta M, Bettini G, Scarpa F, Fiorelli F, Rubini G, et al. (2013) Nodular dermatofibrosis in a dog without a renal tumour or a mutation in the folliculin gene. J Comp Pathol 148: 248-251.

14. Lium B, Moe L (1985) Hereditary Multifocal Renal Cystadenocarcinomas and Nodular Dermatofibrosis in the German Shepherd Dog: Macroscopic and Histopathologic Changes. Vet Pathol 22: 447-455.

15. Ciccarelli S, Di Bello A, Valastro C, Leo C, Lenoci D, et al. (2019) Unilateral renal cystadenocarcinoma and nodular dermatofibrosis in a mixed-breed dog carrying a FLCN gene mutation. Vet Dermatol.

16. Mosenco AS, Culp WT, Johnson V, French A, Mehler SJ (2008) Renal cystadenoma in a domestic shorthair. J Feline Med Surg 10: 102-105. 